\title{
HDAC6 Inhibitor KA2507
}

National Cancer Institute

\section{Source}

National Cancer Institute. HDAC6 Inhibitor KA2507. NCI Thesaurus. Code C135629.

An orally bioavailable inhibitor of histone deacetylase (HDAC) type 6 (HDAC6; HDAC-6), with potential antineoplastic activity. Upon administration, KA2507 targets, binds to and inhibits the activity of HDAC6. This results in an accumulation of highly acetylated chromatin histones, the induction of chromatin remodeling and an altered pattern of gene expression. Specifically, inhibition of HDAC6 prevents STAT3 activity, which leads to a reduction in programmed death-1 (PD-1) expression. Eventually, this results in a selective transcription of tumor suppressor genes, tumor suppressor protein-mediated inhibition of tumor cell division and an induction of apoptosis in tumor cells that overexpress HDAC6. HDAC6, which is upregulated in many tumor cell types, deacetylates chromatin histone proteins. 